\title{
Understanding the vector in order to plan effective tobacco control policies: an analysis of contemporary tobacco industry materials
}

\author{
Anna B Gilmore
}

\section{Correspondence to}

Dr A B Gilmore, Professor of Public Health, Department for Health, University of Bath, Claverton Down Road, Bath BA2 7AY, UK; a.gilmore@bath.ac.uk

Received 23 November 2011 Accepted 19 December 2011

\section{ABSTRACT}

This paper builds on tobacco document research by analysing contemporary materials to explore how the global tobacco market has changed, how transnational tobacco companies (TTCs) are responding and the implications for tobacco control. The methods involved analysis of a variety of materials, including tobacco company annual reports, investor relations materials, financial analyst reports, market research reports and data. Once China, where TTCs have little market share, is excluded, global cigarette volumes are already declining. Nevertheless, industry profits continue to increase. This pattern is explained by the pricing power of TTCs - their ability to increase prices faster than volumes fall, a consequence of market failure. Pricing power is now fundamental to the long term future of TTCs.

Consequently, and in light of growing regulations, the business model of the TTCs is changing. Product innovation is now a key marketing technique used to drive consumers to buy more expensive (ie, profitable) premium cigarettes. Contrary to established wisdom, high tobacco excise rates, particularly where increases in excise are gradual, can benefit TTCs by enabling price (profit) increases to be disguised. Large intermittent tax increases likely have a greater public health benefit. TTC investments in smokeless tobacco appear designed to eliminate competition between smokeless tobacco and cigarettes, thereby increasing the pricing power of TTCs while enabling them to harness the rhetoric of harm reduction. Monitoring TTCs can inform effective policy development. The value maximising approach of TTCs suggests that a ban on product innovation and more informed tobacco excise policies are needed.

\section{INTRODUCTION}

Tobacco document research has produced an important body of literature which has proved essential in holding the industry to account and informing policy development. ${ }^{1}$ This paper aims to build on such research by using more contemporary materials to explore how the global tobacco market has changed in the past 20 years, how transnational tobacco companies (TTCs) are responding and what the implications are for global tobacco control.

These contemporary materials (including company annual reports, investor relations' materials, press coverage, financial analyst and market research reports) provide a means of monitoring tobacco industry activity, as enshrined in Article 5.3 of the Framework Convention on Tobacco Control which requires signatories to protect health policies 'from commercial and other vested interests of the tobacco industry'. ${ }^{2}$ These materials are also available on most companies registered in the west and thus the approach used could be expanded to research other industries (eg, alcohol and food companies). Finally, they provide a more timely analysis of industry activity than is possible through analysis of tobacco documents alone (the most recent of which date to the early 2000s).

\section{METHODS}

In addition to existing academic literature, the paper draws on the analysis of a variety of materials examined from 2007 onwards (although some date from before that) as part of efforts by the University of Bath Tobacco Control Research Group to monitor the business and marketing activities of TTCs. These include company annual reports, investor relations materials and press releases, financial analyst reports (those of Citigroup, Morgan Stanley and Redburn), press coverage and market research reports, and other data (predominantly Euromonitor, although Keynote, Mintel and ERC reports also informed the work). Tobacco industry journals-Tobacco Journal International and Tobacco Reporter (which cover the global tobacco market) - and the retail magazine, The Grocer (which covers just the UK) were also examined.

The paper uses these materials to examine current global tobacco market dynamics, focusing first on cigarettes and then on smokeless tobacco (ST), and within each of these areas, how TTCs are responding. The latter analysis focuses on British American Tobacco (BAT), the world's second largest TTC. This focus is driven by pragmatism: it would be impossible to examine all TTCs in detail within a single paper although examples from other TTCs are provided to illustrate similarities and differences.

\section{RESULTS}

\section{The global tobacco market-cigarettes}

\section{Cigarette volume trends}

In 2010 , an estimated $92 \%$ of revenue in the global tobacco market was generated from cigarettes, ${ }^{3}$ making this the most important sector for TTCs. ${ }^{4}$ Between 1960 and 2000, global cigarette consumption increased by $4 \%$ per annum ${ }^{5}$ (figure 1 ), but since 2000, growth has slowed to under $1 \%$ annually, ${ }^{7-11}$ and from 2015, volume declines are predicted. ${ }^{12}$ Once China is excluded, global volumes are already falling. 7812 


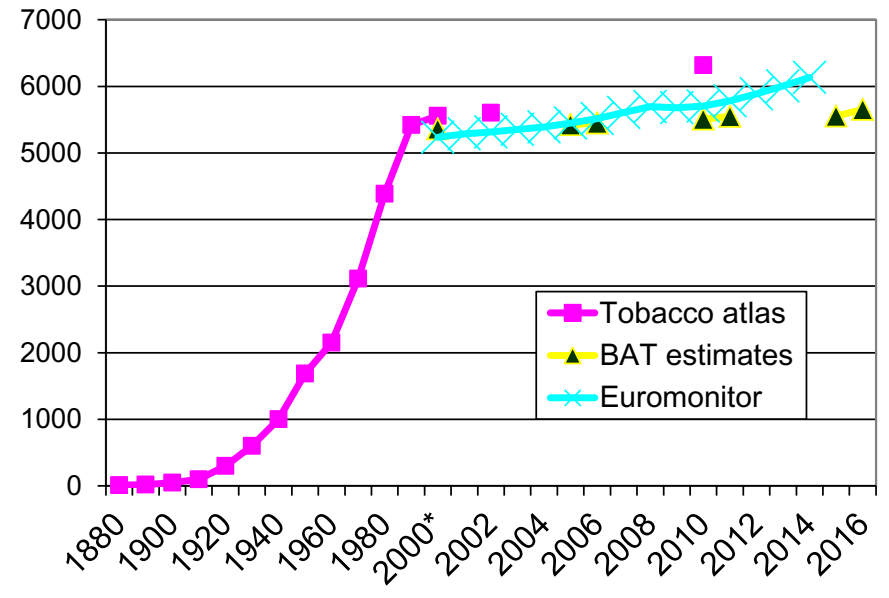

Figure 1 Global cigarette consumption trends and predictions (millions of sticks): 1880-2016. Sources: Tobacco Atlas data, 2010 data from the third edition (2009), ${ }^{5}$ other data from the second edition. ${ }^{6}$ Euromonitor International data downloaded 16 March 2011. British American Tobacco (BAT) data. ${ }^{7-11}$ *Please note the varying scale on the $x$-axis.

This growth slump reflects both improvements in tobacco control and the saturation of opportunities following the industry's successful global expansion and consolidation over recent decades. ${ }^{13-18}$ Most state owned tobacco companies have now been privatised ${ }^{16}$ or the markets opened to TTCs through other means. ${ }^{15} 19$ The world's largest market, China, looks closed to the TTCs: tobacco is apparently excluded from China's World Trade Organisation accession agreement (despite the best efforts of TTCs $)^{20}$ and the licensing agreements reached to date remain insignificant. ${ }^{21}$

\section{Cigarette value trends and pricing power}

The industry's main interest, however, is profits, and despite stagnating sales, profits continue to rise (figure 2). Indeed, perhaps the most remarkable change in the tobacco industry in recent years is the increase in its pricing power: its ability to ensure that prices (and thus profits) increase more quickly than volumes fall. ${ }^{22}$ As explained elsewhere, ${ }^{22}$ this pricing power occurs in large part because tobacco is an addictive product with

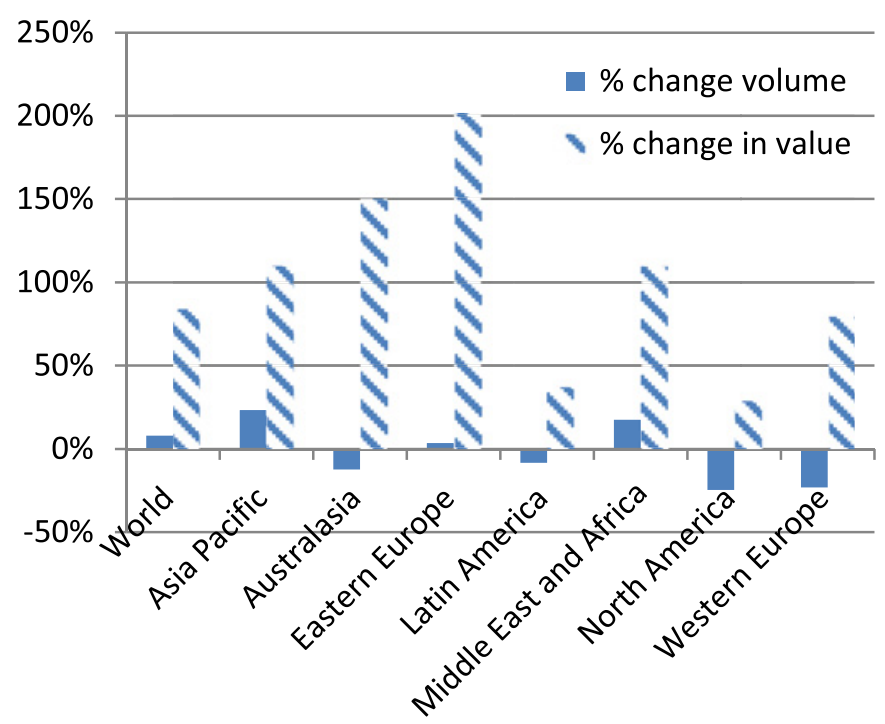

Figure 2 Global cigarette market: per cent change in value and volume overall, and by region, 2001-2010. Source: Euromonitor data. few substitutes and because there is very limited competition in the global tobacco market (just four TTCs-Philip Morris International (PMI), BAT, Japan Tobacco International (JTI) and Imperial Tobacco Group ${ }^{17}$-dominate the global market outside China). This enables the companies to increase prices almost at will, making the manufacture of tobacco products uncommonly profitable and ensuring that profits rise even when volumes fall. $^{22}$

Consequently, the value of global cigarette sales has risen by $84 \%$ in the past decade despite limited volume growth, with marked increases in value seen even in markets experiencing major volume declines (figure 2).

\section{Combining volume and value maximising approaches}

In limited numbers of markets opportunities for volume growth remain, and while this is the case the industry will combine its long term (volume) and short term (value) profit maximising approaches. The latter model predominates in established markets with the profits generated used to subsidise the volume maximising approach typical of emerging markets. (As explored later, although one model may predominate, a combined approach is also taken within individual markets to allow for the differing price sensitivities of smokers.)

\section{Volume maximisation (emerging markets)}

There are three main ways that TTCs can gain volume: entering new markets, acquiring new businesses and pushing up consumption. All are more limited than in the past, particularly the first two, and consequently the current focus is on pushing consumption. Three years ago the priority markets with scope for expanding consumption included Eastern Europe. ${ }^{23}$ With volumes there now declining, the focus has shifted to Asia, Africa and the Middle East ${ }^{324}$ where consumption growth will occur through income and population growth alone, ${ }^{8} 12$ the latter sufficient to increase sales even if smoking prevalence falls. ${ }^{24}$ Further opportunities emerge from shifting smokers of traditional products such as beedis (small, hand rolled cigarettes traditionally used in South Asia) onto white stick cigarettes, and pushing women, who traditionally have lower rates of smoking, to take up the habit. If the former strategy fails, TTCs can move into the beedi market, as occurred with kreteks (traditional clove cigarettes) in Indonesia. ${ }^{25} 26$ It is for these reasons, and because of their sheer size (Asia accounted for $60 \%$ of world cigarette sales in 2010, Euromonitor data downloaded 6 September 2011), that the markets in Asia are key. India, the world's second most populous country, is an excellent example: beedis account for $85 \%$ of total tobacco consumption and female smoking remains low at $4.4 \%$ compared with $24 \%$ in men. ${ }^{24} 27$ Consequently, marketing to women, young people and beedi smokers, assisted by women's empowerment, income and population growth, will provide enormous opportunities.

Evidence from the industry's exploitation of the former Soviet Union in the early 1990s illustrates the aggressive approach of TTCs to volume expansion in emerging markets. TTCs competed aggressively to acquire market share. They lobbied to keep tobacco excise low, sold cigarettes cheaply (including via illicit trade) and marketed heavily, ignoring existing legislation and specifically targeting women. ${ }^{28-33}$ In Russia, smoking rates increased, markedly so in women, the age of first smoking fell and consumption spiralled. ${ }^{30} 34$

Yet BAT indicates that profits did not start accruing in Russia until 2000, ${ }^{3536}$ referring to the approach in the 1990s as 'share at all costs market dynamics'. ${ }^{35}$ Assisted by economic and income growth, BAT began to switch from this 'high volume, low value' 
approach $^{35}$ to a value maximising approach. ${ }^{10} 3536$ The impact this can have on profits is illustrated by BAT's estimation in 2006 that simply shifting sales of 1 billion sticks (by my estimate just 1\% of BAT's Russian market share at that time) from a low priced brand to a premium priced brand would provide an additional $£ 20$ million in revenue. ${ }^{37}$ Consequently, Russia, similar to Ukraine ${ }^{38}$ and most of the Eastern European region it dominates, has in the past few years shifted from being a volume to a value growth market (as figure 2 illustrates, this region shows the most marked value growth in recent years). This suggests the initial aim was to rapidly increase volumes regardless of profits; once volumes were large enough and the regional economies strong enough, prices were increased, the overall plan ensuring long term profits. This model will inevitably be repeated in Asia, the timing of the switch from a volume to a value maximising strategy dependant on economic and regulatory developments. Philip Morris documents and its conduct in Thailand suggest it takes a similar approach. $^{39} 40$

\section{Value maximisation (established markets): marketing to ensure 'willingness to pay a premium ${ }^{41}$}

Global cigarette volume predictions (see above) indicate that the long term future of TTCs is now largely dependent on pushing value rather than volume. ${ }^{342}$ Consequently, and due to growing regulations, marketing and pricing strategies are changing. Increasing restrictions on marketing have increased the importance of retail outlets as a focal point for marketing. Hence developing promotions that work in this forum and building relationships with retailers are now key. ${ }^{41} 43$ More broadly, while the five Ps (product, price, place, person and promotion) remain central, there are nuanced changes in the mix ${ }^{3743}$ :

Right product, right price. To improve marketing efficiency BAT has, for almost 15 years now, been narrowing its previously massive brand portfolio to focus on four 'global drive brands'-Lucky Strike, Dunhill, Kent (premium brands) and Pall Mall (economy brand). ${ }^{37} 44$ More recently, two others, including Vogue (specifically targeted at women), were added. ${ }^{1023}$ These brands have shown remarkable growth, ${ }^{10} 41$ outstripping growth in competitors' main brands. ${ }^{11} 37$ This emphasis on premium brands, shared by other TTCs, has led to premium brands gradually making up a greater share of the global market $^{24}$ (albeit not all individual markets, as explored below). Owing to the considerably greater profitability of premium brands, ${ }^{37}$ this approach maximises profits. ${ }^{44}$

Innovation. Innovation is key to driving sales of these premium brands, and thus profits, by ensuring "willingness to pay a premium'. 1123 4145 Innovation covers both packaging (eg, resealable packs) and product innovations (eg, capsule technology, aromas, new filter technology and superslim products targeted at women) ${ }^{11} 23 \quad 3744 \quad 46$; the latter increasingly central to the marketing efforts of BAT ${ }^{42} 4748$ and other TTCs in the past 5 years $^{464950}$ (see figure 3). In 2010, BAT claimed that over $10 \%$ of sales came from product innovation, of which almost half were new products and variants that did not exist a year previously. ${ }^{52}$ While obviously central to BAT's current marketing strategy, more interesting is the importance of innovation to BAT's business model, ${ }^{41-43}$ being described by BAT's new chief executive as 'fundamental to BAT's value growth'. ${ }^{42}$

A key concern is that these innovations, particularly those focusing on filter design (which have no documented potential in reducing risk), may convey a misleading suggestion of reduced risk akin to the 'light' cigarette debacle. ${ }^{53}$ Indeed, according to
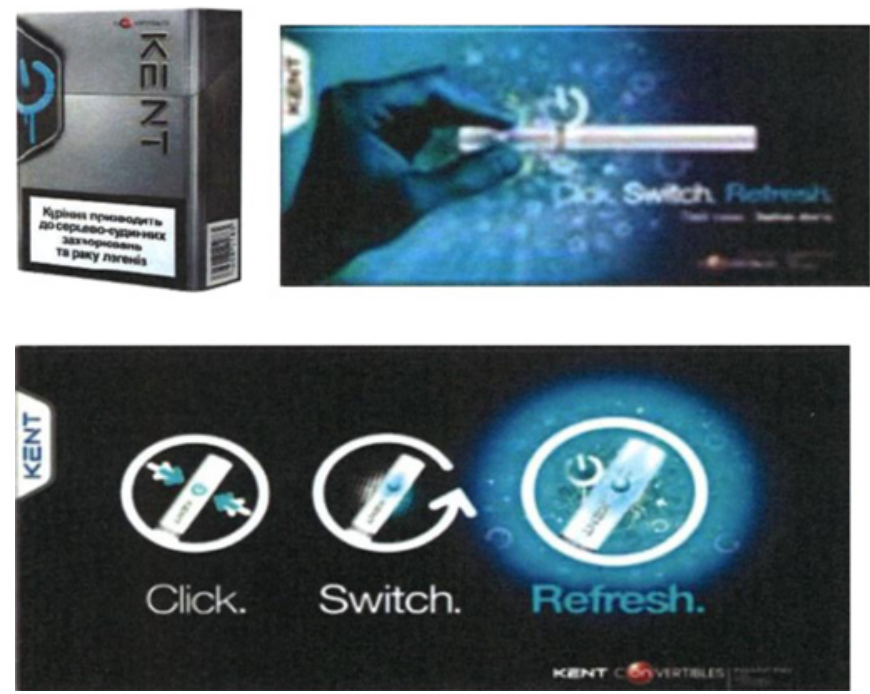

Figure 3 Examples of product innovation. Recent examples include Kent Nanotek with an activated carbon filter, Kent Capsule where a mentholated capsule in the filter can be 'switched on', enabling the user to switch from an unflavoured to a menthol product (see picture). Similar formats are available for other global drive brands - for example, a 'click and roll' version of Lucky Strike (http://hongkongmagician.com/ experience/lucky-strike-click-roll), a brand for whom young smokers comprise $60 \%$ of franchise. ${ }^{41}$ Evidence suggests that more recent launches of innovative products have also enjoyed success in a wide variety of countries. ${ }^{51}$ Japan Tobacco International and Philip Morris International have launched similar products. ${ }^{50}$

Euromonitor, innovation has three purposes-'to justify a premium price, to promise a different experience and to suggest a reduced risk experience' (emphasis added) (Chart 2924).

Right person. As before, ${ }^{54}$ young people remain key to the industry, with the global drive brands all targeted at this age group. ${ }^{44}$ The reason, it appears, is that the young are prepared to pay more for brand value and innovation, whether in the form of lights, menthols, charcoal filters or global drive brands generally. One BAT marketing presentation refers to the need to 'WIN THE ASU30 (adult smoker under 30) CONSUMER', 10 while another labels young smokers as the 'drivers' of shareholder value. ${ }^{37}$ It outlines how these are the smokers likely to switch brand and to pay for expensive brands/brand value; although only $21 \%$ of volume, they account for $30 \%$ of switching volume and $42 \%$ of switching margin whereas older smokers are both less likely to switch and more likely to trade down than up if they do so. ${ }^{37}$

Price and excise policy. Contrary to established wisdom, it appears that the industry's pricing power is, in many countries, facilitated by tobacco excise policies ${ }^{20} 23$ : when tobacco excise rates are high, manufacturer's profits represent only a small share of the retail price and increases in these profits, because they make relatively little contribution to the overall price rise, can be disguised as part of the tax increases. In the words of Morgan Stanley, 'high taxes ....can be good for profits'. ${ }^{8}$ A good example is the UK which, despite having some of the highest taxes in Europe, is one of the region's most profitable markets. ${ }^{17}$ Evidence from Ukraine even suggests that cigarette excise increases can prompt the industry to shift from a volume to a value maximising approach. ${ }^{37}$

Emerging evidence from financial analyst reports, ${ }^{8} 21$ industry documents $^{55}$ and research on industry lobbying ${ }^{56}$ also suggests 
that regular, moderate tax increases can benefit industry while large intermittent tax increases have a greater impact on demand. Analysts, for example, note that 'steady, small tax increases can be helpful for the industry" ${ }^{21}$ while 'large unforeseen increases are one of the most effective means of reducing smoking prevalence'. ${ }^{8}$ As BAT noted back in 1992:

The psychology of smoker demand is such that they are more likely to absorb smaller and more frequent price increases than larger and less frequent price increases. During negotiations with government therefore it is preferable to seek the former excise environment. ${ }^{57}$

\section{Value maximisation: making efficiency savings}

Increasing efficiency-for example, by integrating the supply chain, closing factories and streamlining the brand portfolio ${ }^{58}$-is also key to profit maximisation and has helped BAT address its historical inefficiencies. ${ }^{8} 21234158$ 60-63 Between 2003 and 2007, BAT closed 25 factories, reducing the number of countries it manufactures in from 61 to 40, saving over $£ 1 \mathrm{bn} .^{23} 41$

\section{The hidden agenda: cheap tobacco products}

Although TTC presentations to analysts barely mention the value end of the market, ${ }^{64}{ }^{65}$ in mature markets, despite the heavy marketing of premium brands, use of cheap tobacco products is growing 48 66-69 as is the use of price within the marketing mix. ${ }^{70-72}$ In the UK, for example, TTCs have launched a number of 'ultra low price' variants of existing cigarette brands since 2006 (28 brands including 85 sub-brands are now available in this price segment). ${ }^{73-75}$ These cheap products appear to stop price sensitive smokers from quitting (key during a recession ${ }^{46}$ ) and are also likely to provide a route into smoking given the price sensitivity of the young. ${ }^{67}$ This implies that, just as the industry's global approach combines short and long term profit maximising approaches across markets, the same combination is applied within individual markets: at the top end, TTCs increase prices over and above the tax increases (ie, overshift the taxes thus increasing profits), while using these profits to enable them to absorb tax increases (rather than pass them on in full to the consumer) on the cheap brands. ${ }^{67}$

Innovation is also important in this value segment ${ }^{50}$ where various forms of make your own cigarettes have been launched in an apparent attempt to undermine tax policy. ${ }^{76} 77$ For example, 'singles' (pre-made cylinders of tobacco) were taxed as loose tobacco rather than (the more heavily taxed) ready made cigarettes when launched in Germany until this practice was overruled. ${ }^{78}$ In the UK, Imperial Tobacco launched a new make your own product immediately following the 2011 annual increase in cigarette duties. ${ }^{76} 77$

\section{The global tobacco market-smokeless tobacco}

While previous decades were characterised by frequent mergers and acquisitions in the cigarette sector, ${ }^{17}$ the past few years have seen a switch in emphasis to ST and, very recently, nicotine, ${ }^{79} 80$ as explored elsewhere in this edition. ${ }^{18}$ All four TTCs have now acquired significant ST interests or established joint ventures with ST manufacturers to the extent that no major ST companies now remain independent. ${ }^{81}$

ST sales have been growing more rapidly than cigarettes (a $51 \%$ increase in global volumes compared with $8 \%$ in cigarettes from 2001 to 2010) and are predicted to continue increasing. ${ }^{147}$ This is, however, occurring from a far lower base, and in 2010 just $2 \%$ of revenue from the global tobacco market was generated by $\mathrm{ST}^{3}$

\section{Rhetoric of 'responsibility' and harm reduction}

\section{Corporate social responsibility}

'Responsibility' is one of three main elements in BAT's business strategy, ${ }^{43} 82$ suggesting it is essential to BAT's future. Responsibility features heavily in its public messaging 708283 yet what appears under the rubric of responsibility is telling: harm reduction, reputation management, 'sensible regulation', standards of business conduct and business principles. 1082 'Sensible regulation' is described as 'proactively shaping an environment to succeed' with reference made to building trust and gaining stakeholders for dialogue, the aim apparently to move 'from dialogue to evolving cooperation'? 10 A BAT presentation on Russia implies that responsibility means being the 'government's trusted partner'. ${ }^{83}$ These presentations thereby make explicit that BAT's corporate social responsibility (CSR) strategy has little to do with responsibility and is instead a political strategy aiming to ensure access and influence. ${ }^{84} 85$

\section{Harm reduction}

While harm reduction features as part of BAT's responsibility strategy, unlike other aspects of this strategy, details are rarely fleshed out ${ }^{1023}$ and, despite its recent investments in ST, ST is virtually absent from BAT's business plan. This suggests that BAT has little intention of pushing ST in the short term (outside markets such as the USA where ST use is already well established). Indeed, BAT recently scaled back its snus test markets ${ }^{86}$ suggesting that snus may not take off in countries where ST use is not already well established. Similarly, PMI's chief financial officer, when speaking about its joint venture with snus manufacturer Swedish Match, suggested PMI had little intention of pushing ST in the short term given the profitability of cigarettes:

It's something that will do us very good in the long term. This is why we went into this joint venture. ...... The big profitability pools in the international tobacco world, often are, and continue to be, in the cigarette category. But you always need to be one step ahead, which is why we went into this joint venture. ${ }^{87}$

Nevertheless, BAT's rhetoric on harm reduction is ever present, featuring prominently on the company's main website, an additional website dedicated to BAT's research on reduced risk products (http://www.bat-science.com) in responses to consultations and press briefings. ${ }^{88} 89$ Furthermore, BAT's latest presentation on harm reduction suggests its motives may be more underhand, with success in harm reduction predicted to include ' $[\mathrm{m}]$ ore marketing freedoms and enhanced brand equity enabled by regulatory and political support' and '[n]ew "would be smokers" begin with and stay with low risk product categories'. ${ }^{90}$ The last point echoes BAT's documents from the $1970 \mathrm{~s}$ and 1980s which identified that ST provided an opportunity to encourage those who would no longer take up smoking (due to health concerns) to take up ST instead; that is, to create a new epidemic. $^{91}$

\section{DISCUSSION \\ Key findings}

This paper shows that the global cigarette market has changed in key ways. First, once China is excluded from the figures, global consumption is falling and the opportunities are increasingly about driving value rather than volume. Second, the industry is able to increase profits in the face of declining sales due to its phenomenal pricing power which is now fundamental to its future. Volumes are, however, still growing in some 
countries and consequently the industry is pursuing two models of growth: a traditional volume maximising model where volumes are pushed at almost any cost and a profit maximising model that drives prices upwards (facilitated by high tobacco excise duties) and pushes consumers to smoke expensive brands using product innovation as a marketing strategy. The first model predominates in emerging markets and the second in established markets, although most inevitably include a mix of these models with the profits generated in the second used to subsidise the first. Third, TTCs, which were until recently effectively cigarette companies, have become tobacco and nicotine companies having invested so significantly in the ST market that there are now no large independent ST companies left. This appears to have been a defensive move designed to eliminate competition between ST and cigarettes, enhance pricing power and provide a sector with volume growth (reassuring investors) and long term security should regulation finally start to threaten profitability from cigarettes.

\section{Implications for policy and practice}

Many of the issues outlined above can be addressed through full implementation and enforcement of the Framework Convention on Tobacco Control. This section therefore focuses on specific elements within that, or more novel options.

\section{Emerging markets}

In emerging markets there is still potential to constrain the size of the tobacco epidemic and, through this, the industry's long term future. Preventing marketing (including the launch of new brands targeted at women) and the industry's ability to sell tobacco cheaply are vital. Morgan Stanley notes that 'anti-smoking legislation specifically aimed at women in emerging markets could provide the greatest single impediment to industry growth'. Targeting resources at the fastest growing markets in volume terms (Asia, Africa and the Middle East) will help, but so too will reducing tobacco use in the most profitable markets, thereby reducing funds available to subsidise expansion elsewhere.

\section{All markets}

Interventions that challenge the industry's ability to grow value are now the industry's greatest threat. ${ }^{11} 21$ There are a number of regulatory options that the evidence above suggests should be considered.

\section{Further marketing controls}

Product innovation is a particular concern given that it may be used to convey a misleading message of reduced risk, just as light cigarettes did in the past and, in the value segment, to undermine the impact of tax increases, and because young people remain a marketing target. The tobacco market should be frozen as it is currently and no new products or brand variants introduced unless they can show significant health benefits. Given that BAT has been working on a reduced risk cigarette for decades yet still not produced one, this scenario is unlikely. Such regulation would close the industry's main marketing tactic in countries where tobacco advertising is otherwise restricted. Uruguay has legislation that resembles this-it requires that each tobacco brand may only possess a single form of presentation. ${ }^{92}$

The public health community should recognise and work with retailers as an important means of communicating with smokers, just as industry does. There is a need to understand the retail margin on tobacco versus other products (including quit products), and to explore how this might be used to encourage retailers to disseminate quit messages and products.

\section{A more informed excise policy}

We must recognise that (in high tax markets at least) the industry is not opposed to price increases per se but wants this to occur via its own price increases and not via tax increases. Evidence shows it has used the threat of increased smuggling to contain tax increases and instead, in direct contradiction to its lobbying stance, increased prices itself, ${ }^{93}$ thus ensuring that its profits and not government revenues increase. While high prices are good for public health, the industry's ability to do this represents a missed opportunity for governments to raise taxes and revenue. Empirical research is needed to explore the impact of large intermittent versus small gradual tax increases. Such work should examine impacts on consumption, prevalence, inequalities in smoking and government revenue. In the interim, further consideration should be given to implementing large rather than small gradual tax increases.

\section{Price cap regulation}

Price cap regulation could address many of the problems identified in this paper. ${ }^{22}$ The proposal for price cap regulation emerged from concerns about the extent of market failure and the resulting excess TTC profits. Under such a system, well established in the utilities sector, industry profits would be capped and the excess profits transferred to the government as additional excise revenue while maintaining high tobacco prices for consumers. This would produce significant additional government revenue ${ }^{94}$ and, by reducing industry profit, remove the TTCs' incentive and ability to oppose tobacco control policies and offset losses in emerging markets through the excess profits generated elsewhere. ${ }^{22}$ It could thereby curtail the ultimate size of the global tobacco epidemic.

Price cap regulation would also remove the industry's ability to use price as a marketing tool, provide a means of controlling cigarette smuggling (because the industry could only profit from legal sales) and prevent underhand marketing by limiting or eliminating the marketing budget. ${ }^{22}$

\section{Addressing corporate social responsibility}

The paper provides further evidence that CSR must be recognised as a political activity ${ }^{84} 85$ by indicating that BAT's ongoing focus on CSR is essential to its ability to maintain sufficient credibility to participate in policy debates. The tobacco control community must therefore continue its efforts to expose TTC tactics as a counterbalance to this investment in CSR. ${ }^{95}$

\section{Harm reduction}

While evidence suggests that ST could be part of an effective harm reduction strategy, ${ }^{96} 97$ this paper highlights the need to understand the industry dimension. It suggests there are three major implications of recent TTC investments in ST and nicotine. First, TTCs now control the market for most cigarette substitutes, further restricting competition in the tobacco sector and enhancing pricing power of TTCs. Second, in contrast with cigarettes, ST and nicotine offer potential long term volume growth and thus reassurance to investors who, experts suggest, will ultimately become nervous about investing in a sector without volume growth. ${ }^{98}$ Third, these investments allow TTCs to harness the rhetoric of harm reduction, which has potential to secure access and influence, despite appearing to have little genuine intention of pushing ST products in the short term and the limited uptake of snus in markets where ST is not already established. As such, TTCs have turned ST from a threat (a product that could have competed with cigarettes) to an opportunity. Ensuring ST is adequately regulated and that 
conflicts of interest are addressed if and when TTCs launch a pure nicotine product will be essential to controlling the tobacco epidemic long term.

\section{Efficiency savings and implications for impact assessments}

Requirements to cost the impacts of regulation on business, via business impact assessments, are growing. While properly conducted impact assessments can be a vital part of effective policy making and have been widely used in environmental and public health, it is noteworthy that BAT, working with a broad group of other industries, specifically promoted the use of business impact assessments which use a cost benefit analysis approach because it felt they could help prevent the passage of public health policies and legislation. ${ }^{99} 100$ Evidence presented above on the extent of recent efficiency savings combined with evidence that further efficiency savings are predicted, ${ }^{23} 58$ underlines the importance of accounting for such savings when assessing policy impacts (eg, by accounting for underlying trends in factory numbers and employment levels). This is reinforced by evidence of the industry's willingness to exaggerate the costs of regulation ${ }^{100-102}$ and misrepresent planned factory closures ${ }^{59}$ as a direct cost of regulation. ${ }^{103}$ Furthermore, any costs must be put in the context of the industry's significant profits although attempts to do this ${ }^{102}$ have inevitably met with industry opposition. ${ }^{104}$

\section{Limitations}

The paper has focused on BAT. While the global market context is identical for all TTCs, there may be differences in the nature of each company's response. For example, Imperial Tobacco relies more on cheaper brands than BAT, has invested less in research and is less able to innovate; these issues could threaten its long term profitability compared with other TTCs. ${ }^{50} 85 \mathrm{It}$, like PMI, also appears to have less scope for efficiency savings than BAT. ${ }^{105}$ The evidence presented will not necessarily apply to companies operating within specific markets, such as the USA. The issue of harm reduction is, for example, quite different there as ST use is already well established. Finally, it has been

\section{What this paper adds}

- Much has been learnt from tobacco industry document research and it has proved essential to holding the tobacco industry to account.

- This paper illustrates the way in which more contemporary industry materials can be used to monitor and analyse both the global tobacco market and current tobacco industry actions and how this information can be used to inform public health policy development.

It shows inter alia that:

- Once China is excluded, global cigarette volumes are already declining but that, despite this, industry profits continue to increase.

- This pattern is explained by the industry's pricing power-its ability to increase prices faster than volumes fall. This pricing power is a consequence of market failure and is now fundamental to the industry's long term future which is now largely reliant on value not volume growth.

- Understanding this profit and value dimension is essential to understanding industry conduct and planning effective tobacco control interventions. impossible to address all of the current complexities in tobacco control policy making that emerge through industry manipulation. A key omission is cigarette smuggling which will be addressed in a separate paper.

\section{CONCLUSION}

This paper highlights the complex tensions between volume and value, cigarettes and ST, harm reduction and CSR, and how an understanding of the motives and tactics of TTCs can inform policies, avoid pitfalls in policy development and ensure prompt policy responses to emerging issues. The public health community, by actively shaping the regulatory environment, has the potential to shape the future of the cigarette and ST epidemics.

Funding This work is supported by grant No R01CA160695 from the United States National Cancer Institute. The ongoing industry monitoring that informs this paper is supported by funding from Cancer Research UK (grant No C27260/A12294) (http://www.cancerresearchuk.org) and Smokefree South West. ABG is supported by a Health Foundation Clinician Scientist Fellowship and is a member of the UK Centre for Tobacco Control Studies (UKCTCS), a UK Centre for Public Health Excellence which is supported by funding from the British Heart Foundation, Cancer Research UK, the Economic and Social Research Council, the Medical Research Council and the National Institute of Health Research, under the auspices of the UK Clinical Research Collaboration. The funders played no role in the study design, analysis and interpretation of the data, or writing of the report, or the decision to submit the article for publication. The content is solely the responsibility of the author and does not necessarily represent the official views of the funders.

Competing interests None.

Provenance and peer review Commissioned; externally peer reviewed.

\section{REFERENCES}

1. Glantz SA. The truth about big tobacco in its own words. BMJ 2000;321:313-14. http://www.ncbi.nlm.nih.gov/entrez/query.fcgi?cmd=Retrievegdb=

PubMed\&dopt $=$ Citationylist uids $=10926570$

2. World Health Organization. Guidelines for implementation of Article 5.3 of the WHO Framework Convention on Tobacco Control on the protection of public health policies with respect to tobacco control from commercial and other vested interests of the tobacco industry. Conference of the Parties to the FCTC, 2008. http://www. who.int/fctc/guidelines/article 5 3.pdf (accessed 18 Jun 2009)

3. Euromonitor. Global Tobacco Findings 2011: Battle Intensifies. Euromonitor, 2011

4. Euromonitor. Global Tobacco-Key findings Part One-Tobacco Overview and Cigarettes-Resilience or Decline? Euromonitor, 2010.

5. Shafey 0, Eriksen M, Ross H, et al. The Tobacco Atlas. 3rd edn. Georgia: American Cancer Society, 2009.

6. Mackay J, Eriksen M, Shafey 0. The Tobacco Atlas. 2nd edn. Georgia: American Cancer Society, 2006.

7. Stevens B. Deutsche Bank Global Retail and Consumer Conference. Paris 12th June 2007. Paris: British American Tobacco, 2007. http://www.bat.com/group/ sites/uk_3mnfen.nsf/vwPagesWebLive/D07C3DXU/\$FILE/medMD744C4E.pdf? openelement (accessed 13 Sep 2011).

8. Morgan Stanley. Tobacco-late to the party. Morgan Stanley Research Europe. London: Morgan Stanley, 2007.

9. Euromonitor International Data. 2011

10. Levy J. Welcome to BAT-Central and Eastern Europe. Growing global drive brands with passion, speed and rigour. Lausanne, 2007. http://www.bat.com/group/sites/ uk 3mnfen.nst/vwPagesWebLive/D07C3DXU/\$FILE/medMD74LL6Y.pdf?openelement

11. Rayner P. Introduction and overview. Investor visit to Hong Kong and Vietnam May 2007. 2007. http://www.bat.com/group/sites/uk 3mnfen.nsf/vwPagesWebLive/ D07C3DXU/\$FILE/medMD73FJDU.pdf?openelement (accessed 13 Sep 2011).

12. Euromonitor. The future of tobacco. Euromonitor International, 2011.

13. Gilmore A, Fooks G, McKee M. The IMF and tobacco: a product like any other? Int J Health Serv 2009;39:789-93. http://www.ncbi.nlm.nih.gov/pubmed/19927416

14. Connolly GN. Worldwide expansion of transnational tobacco industry. J Natl Cancer Inst Monogr 1992;12:29-35.

15. Chaloupka FJ, Laixuthai A. U.S trade policy and cigarette smoking in Asia. Cambridge: National Bureau of Economic Research, 1996.

16. Gilmore $\mathbf{A B}$, Fooks G, McKee M. A review of the impacts of tobacco industry privatisation: implications for policy. Glob Public Health 2011;6:621-42. http://dx. doi.org/10.1080/17441692.2011.595727

17. Hedley D. Consolidation endgame in sight-but is there one more big throw of the dice? Euromonitor, 2007. http://www.euromonitor.com/Consolidation endgame in sight but is there one more big throw of the dice

18. Aguinaga Bialous $\bar{S}$, $\overline{\text { Peeters }} \overline{\mathrm{S}}$. A brief overview of the tobacco industry in the last 20 years. Tob Control 2012;21:92-4.

19. Gilmore A, Österberg E, Heloma A, et al. Free trade versus the protection of health: the examples of alcohol and tobacco. In: MacLehose L, McKee M, Nolte E, eds. 
Health policy and European Union enlargement. Maidenhead: Open University Press, 2004.

20. Holden C, Lee K, Gilmore A, et al. Trade policy, health, and corporate influence: British American tobacco and China's accession to the World Trade Organization. Int $J$ Health Serv 2010;40:421-41.

21. Spielman A. European tobacco. The startling business of tobacco. London: Citigroup, 2008

22. Gilmore AB, Branston JR, Sweanor D. The case for OFSMOKE: how tobacco price regulation is needed to promote the health of markets, government revenue and the public. Tob Control 2010;19:423-30. http://tobaccocontrol.bmj.com/content/19/5/ 423.abstract

23. Stevens B. Morgan Stanley Consumer Retail Conference. New York: British American Tobacco, 2008. http://www.bat.com/group/sites/uk_3mnfen.nsf/ vwPagesWebLive/D06FKEVZ/\$FILE/medMD7LJDOT.pdf?openelement (accessed 13 Sep 2011).

24. Euromonitor. Global tobacco: survival strategies for a savage market. 2008. http:// www.euromonitor.com/Global Tobacco Survival Strategies for a Savage Market

25. Euromonitor. Passport: tobacco in Indonesia. Industry overview. Euromonitor, 2011.

26. Hurt RD, Ebbert JO, Achadi A, et al. Roadmap to a tobacco epidemic: transational tobacco companies invade Indonesia. Tob Control 2011. http://tobaccocontrol.bmj. com/content/early/2011/08/18/tc.2010.036814.full.pdf

27. Euromonitor. Tobacco in India. Euromonitor International, 2011.

28. Gilmore A, Radu-Loghin C, Zatushevski I, et al. Pushing up smoking incidence: plans for a pirvatised tobacco industry in Moldova. Lancet 2005;365:1354-9.

29. Gilmore A, Collin J, McKee M. British American Tobacco's erosion of health legislation in Uzbekistan. BMJ 2006;332:355-8.

30. Perlman F, Bobak M, Gilmore A, et al. Trends in the prevalence of smoking in Russia during the transition to a market economy. Tob Control 2007:16:299-305.

31. Gilmore A, Collin J, Townsend J. Transnational tobacco company influence on tax policy during privatization of a state monopoly: British Tobacco and Uzbekistan. Am J Public Health 2007;97:2001-9.

32. Gilmore A, McKee M. Exploring the impact of foreign direct investment on tobacco consumption in the former Soviet Union. Tob Control 2005:14:13-22.

33. Gilmore A, McKee M. Tobacco and transition: an overview of industry investments, impact and influence in the former Soviet Union. Tob Control 2004c;13:136-42.

34. Gilmore A, Pomerleau J, McKee M. Prevalence of smoking in 8 countries of the former Soviet Union: results from the living conditions, lifestyles and health study. Am J Public Health 2004:94:2177-87.

35. Wheaton K. Acquisition to achievement. BAT Group Strategy in Russia. Deutsche Bank Conference. Paris, 2008. http://www.bat.com/group/sites/uk 3mnfen.nsf/ vwPagesWebLive/D06FKEVZ/\%24FILE/medMD7FOKTW.pdf?openelement (accessed 15 Sep 2011).

36. British American Tobacco. British American Tobacco Russia. Rome, 2005. http:// www.bat.com/group/sites/uk_3mnfen.nsf/uwPagesWebLive/DO7C3DXU/\$FILE/ medMD6FDLDD.pdf?openelement (accessed 18 Nov 2011).

37. De Minckwitz C. British American Tobacco Marketing: strategy and brands. Citigroup Tobacco Conference, 2006. http://www.bat.co.uk/group/sites/ uk 3mnfen.nsf/vwPagesWebLive/D07C3DXU/\$FILE/medMD6W3EVR.pdf? openelement (accessed 18 Nov 2011).

38. Ross H, Stoklosa M, Krasovsky K. Economic and public health impact of 2007-2010 tobacco tax increases in Ukraine. Tob Control 2011. http:// tobaccocontrol.bmj.com/content/early/2011/06/14/tc.2010.040071.abstract

39. Anon. Philip Morris. 1993: 2045979119/2045979251. http://legacy.library.ucsf edu/tid/lnm50b00 (accessed 18 Nov 2011).

40. Vateesatokit $\mathbf{P}$, Hughes $B$, Ritthphakdee B. Thailand: winning battles, but the war's far from over. Tob Control 2000:9:122-7. http://tobaccocontrol.bmi.com

41. British American Tobacco. Annual Report and Accounts 2007. British American Tobacco, 2007. http://www.bat.com/annualreport2007 (accessed 13 Sep 2011).

42. Durante N. A proven strategy. BAT Investor Day Hampshire. 2011. http://www.bat. com/servlet/SPMerge?mainurl=\%2Fgroup\%2Fsites\%2Fuk\%5F\%5F3mnfen\%2Ensf\% 2FvwPagesWebLive\%2FDO6FKEVZ\%3Fopendocument\%26amp\%3BSKN\%3D1 (accessed 18 Nov 2011).

43. British American Tobacco. British American Tobacco Annual Report 2010. 2010 http://www.bat.com/ar/2010/downloads/index.html (accessed 18 Nov 2011).

44. Adams P. Merill Lynch International Tobacco Field Trip. London: British American Tobacco, 2003. http://www.bat.com/group/sites/uk_ 3mnfen.nsf/ vwPagesWebLive/DO7C3DXU/\$FILE/medMD6FEHXD.pdf?openelement laccessed 13 Sep 2011).

45. Kwan Yuk P. "Innovation fires up BAT's chief”. Financial Times 9 May 2009. http:// www.bat.com/group/sites/uk 3mnfen.nsf/vwPagesWebLive/D07RZH4E? opendocument\&SKN=1 (accessed 6 Nov 2011).

46. Euromonitor International. Global tobacco: where next for the major players. London: Euromonitor International, 2009.

47. Euromonitor International. Global tobacco-key findings part two-other tobacco products. Overview and competive environment. London: Euromonitor International, 2010.

48. Spielman A, Loveless J, Nobuyoshi M. More down-trading across W Europe in tobacco, according to AC Nielsen data. Citigroup Global Market, 2009.

49. Euromonitor International. Global tobacco: new product developments - regional and country overview. Euromonitor International, 2009.
50. Euromonitor International. Global tobacco: new product developments - creativity in adversity. Euromonitor International, 2009

51. Cobben M. Capsule rollout. British American Tobacco, 2011. http://www.bat.com/ group/sites/UK 8GLKJJ.nsf/vwPagesWebLive/ 3FF4B58C81321BC8C12578880056EF37/\$FILE/14_Mark\%20Cobben\%20-\% 20Capsule\%20Rollout.pdf?openelement (accessed 18 Nov 2011).

52. Levy J. Innovations overview. BAT Investor Day. Hampshire, 2011. http://www.bat. com/servlet/SPMerge?mainurl=\%2Fgroup\%2Fsites\%2Fuk\%5F\%5F3mnfen\%2Ensf\% 2FvwPagesWebLive\%2FD06FKEVZ\%3Fopendocument\%26amp\%3BSKN\%3D1 (accessed 18 Nov 2011)

53. Anderson SJ, Ling PM, Glantz SA. Implications of the federal court order banning the terms "light" and "mild": what difference could it make? Tob Control 2007;16:275-9. http://tobaccocontrol.bmj.com/content/16/4/275.abstract

54. Ling PM, Glantz SA. Why and how the tobacco industry sells cigarettes to young adults: evidence from industry documents. Am J Public Health 2002:92:908-16.

55. Bingham P. Note from Paul Bingham to $B$ Ryan regarding area paper on excise taxation. In: Tobacco BA, ed. 1990:501572229-43. http://legacy.library.ucsf.edu/ tid/qam34a99

56. Shirane R, Smith K, Ross H, et al. Tobacco industry influence in the Czech Republic: manipulating tobacco excise tax and tobacco control policies in times of major political change. PLoS Med. In press.

57. Bingham P. Key area paper: excise taxation of tobacco products. 1992:503923191-215. http://legacy.library.ucsf.edu/tid/mkn70a99

58. Stevens B. Performance against the strategy. BAT Investor Day. Hampshire, 2011 http://www.bat.com/servlet/SPMerge?mainurl=\%2Fgroup\%2Fsites\%2Fuk\%5F\% 5F3mnfen\%2Ensf\%2FvwPagesWebLive\%2FD06FKEVZ\%3Fopendocument\%26amp\% 3BSKN\%3D1

59. Bowles J. Margin improvement in Western Europe. BAT Investor Day. Hampshire, 2011. http://www.bat.com/servlet/SPMerge?mainurl=\%2Fgroup\%2Fsites\%2Fuk\% 5F\%5F3mnfen\%2Ensf\%2FvwPagesWebLive\%2FD06FKEVZ\%3Fopendocument\% 26amp\%3BSKN\%3D1 (accessed 18 Nov 2011).

60. Freedman M. The tobacco industry is aiming at new markets, and BAT is an old hand at lighting them up. 2007. http://www.forbes.com/global/2007/0618/022 print.html

61. Raynor P. Analysts visit to Rome 10th-11th May. British American Tobacco, 2005. http://www.bat.com/group/sites/uk_3mnfen.nsf//wPPagesWebLive/D07C3DXU/ \$FILE/medMD6FDJN2.pdf?openelement (accessed 13 Sep 2011).

62. Brooks N. NBD Strategy. British American Tobacco: 203481260-203481264. http://legacy.library.ucsf.edu/tid/gpi41a99/pdf (accessed 15 0ct 2011).

63. Barton H. Draft BAT industries tobacco strategy (Tobacco Strategy Group 19th May 1993, Agenda item 7). 1993. Bates No: 203469465-203469485. http://legacy. library.ucsf.edu/tid/nil40a99/pdf (accessed 15 Oct 2011).

64. Imperial Tobacco Group PLC. Morgan Stanley Global Consumer Conference. 2011. http://www.imperial-tobacco.com/files/conference/morgan_stanley_ conference slides.pdf

65. British American Tobacco. Investor day. 2011. http://www.bat.com/servlet/ SPMerge?mainurl=/group/sites/uk_8glkjf.nsf/vwPagesWebLive/DO8MTDLN? opendocument\&SKN $=1$

66. Keeler TE, Hu TW, Barnett PG, et al. Do cigarette producers price discriminate by state? An empirical analysis of local cigarette pricing and taxation. J Health Econ 1996:15:499-512.

67. Gilmore A, Tavakoly B, Taylor G, et al. PPACTE Milestone 5.3. A Report on tobacco industry pricing, product substitution and downtrading in the British tobacco market. Dublin: PPACTE, 2011.

68. Tauras JA, Peck RM, Chaloupka FJ. The role of retail prices and promotions in determining cigarette brand market shares. Rev Ind Organ 2006;28:253-84. http:// www.springerlink.com/content/u41q821xp54r524l/

69. Sullivan R. The effect of cigarette taxation on prices: an empirical analysis using city-level data. New York: Syracuse University, 2010. http://rssulliv.mysite.syr.edu/ 10 12_09The\%20Effect\%20of\%20Cigarette\%20Taxation\%20on\%20Prices.pdf (accessed 22 Aug 2011).

70. Moodie C, Hastings G. Making the pack the Hero, tobacco industry response to marketing restrictions in the UK: findings from a long-term audit. Int $J$ Ment Health Addiction 2009;9:24-38.

71. Garman K, Tavakoly B, Gilmore A. UK: price-based promotions target poor. Tob Control 2010;19:263-6.

72. IARC. IARC Handbooks of Cancer Prevention: Tobacco Control. Effectiveness of price and tax policies for control of Tobacco. vol 14. Lyon, France: International Agency for research on Cancer, 2011.

73. Hook S. Laugh? I've change from a fiver! The tobacco industry struggles bans, advertising constraints and government duties, but low-priced and roll-your-own cigarettes are lighting the way. The Grocer 25 February 2006.

74. Spielman A, Loveless J. Mixed picture in European tobacco, according to $A C$ Nielsen data. New York: Citigroup Global Market, 2009.

75. Sheetal M. Category report: tobacco — budget brands soar. Talking retail. London: Metropolis International Group Ltd, 2006. http://www.highbeam.com/doc/1G1116140250.html

76. Talking Retail. Imperial tobacco push for 'make your own' cigarettes. 2011. http:// www.talkingretail.com/products/product-news/imperial-tobacco-push-for-makeyour-own-cigarettes (accessed 18 Nov 2011)

77. London Stock Exchange Regulatory News Service (ARNS). Imperial Tobacco Group Announcment re singles. 18 Nov 2005. http://www.investegate.co.uk/article. aspx?id=200511181200363541U 
78. AFX UK Focus. Imperial Tobacco 'disappointed' with EU cigarette tax ruling. 2005. http://www.iii.co.uk/investment/detail?type=news\&code=cotn\%3AIMT. Lqit=garticleid $=5461536$ gaction $=$ article (accessed 18 Nov 2011).

79. Jacobs S. Persuit of a safer cigarette gathers pace. Financial Times 1 June 2011.

80. Gay G. Shifting Gears. Tobacco Reporter 2011:54-6.

81. Peeters S, Gilmore A. How online sales and promotion of snus contravenes current European Union legislation. Tob Control. Published Online First: 2012. doi:10.1136/ tobaccocontrol-2011-050209

82. De Castro Antonio Monteiro. Analysts' visit to Rome 10th-11th May 2005. 2005. http://www.bat.com/group/sites/uk_3mnfen.nsf/vwPagesWebLive/D07C3DXU/ \$FILE/medMD6FDJN2.pdf?openelement (accessed 15 Sep 2011).

83. British American Tobacco. British American Tobacco Russia. Rome: British American Tobacco, 2005

84. Fooks GJ, Gilmore $A B$, Smith KE, et al. Corporate social responsibility and access to policy Élites: an analysis of tobacco industry documents. PLoS Med 2011:8: e1001076. http://dx.doi.org/10.1371\%2Fjournal.pmed.1001076

85. Tesler LE, Malone RE. Corporate philanthropy, lobbying, and public health policy. Am J Public Health 2008;98:2123-33. http://ajph.aphapublications.org/cgi/ content/abstract/98/12/2123

86. British American Tobacco. Smokeless tobacco. http://www.bat.com/group/ sites/uk_ 3mnfen.nst/vwPagesWebLive/DO6CKJNP?opendocument\&SKN=1 (accessed 15 Nov 2011).

87. Philip Morris International. Webcast PMI Inc Presents at Barclays Back-toSchool Consumer Conference. 2010. http://investors.pmi.com/phoenix.zhtml? $c=146476 \& p=$ irol-eventDetails\&Eventld $=3320737$

88. British American Tobacco. British American Tobacco response to the Department of Health Discussion Document. "Consultation on the future of tobacco control, May 2008. 2008. http://www.bat.com/group/sites/uk 3mnfen.nst/vwPagesWebLive/ D07J7CSX/\$FILE/medMD7J7CUJ.pdf?openelement

89. British American Tobacco Australia (BATA). Plain packaging now heads to High Court. British American Tobacco Australia, 2011. http://www.bata.com.au/ group/sites/BAT 7WYKG8.nsf/vwPagesWebLive/D07WZEX6?opendocument\& SKN=1 (accessēe 18 Nov 2011)

90. O'Reilly D. Harm reduction. BAT Investor Day, 17-18 May 2011. Hampshire, 2011. http://www.bat.com/servlet/SPMerge?mainurl=/group/sites/uk__glkjf.nsf/ vwPagesWebLive/D08MTDLN?opendocument\&SKN=1

91. Peeters S, Gilmore A. A report on the tobacco industry rationale and approach to expand sales of smokeless tobacco (snus) in the European Union. Dublin: Peeters Smokeless Tobacco PPACTE report, 2011.

92. Campaign for Tobacco Free Kids. Country details for Uruguay. 2011. http:// www.TobaccoControlLaws.org. http://www.tobaccocontrollaws.org/country/ Uruguay (accessed 18 Nov 2011).
93. Howell F. The hypocrisy of the Irish tobacco industry on the impact of price rises on tobacco. Amsterdam: European Conference Tobacco or Health, 2011. http://ectoh. org/documents/4B.2\%2OHowell\%20Teh\%20hypocrisy\%20of\%20the\%20lrish\% 20tobacco\%20industrys\%20stance\%20on\%20price\%20increases $\% 20 f o r \%$ 20tobacc0\%20products.pdf

94. Branston R, Gilmore A. The Case for OFSMOKE: the potential for price cap regulation of tobacco to raise $£ 500 \mathrm{~m}$ per year in the UK. Tob Control. In press.

95. Malone RE, Grundy 0, Bero LA. Tobacco industry denormalisation as a tobacco control intervention: a review. Tob Control 2012:21:162-70.

96. Tobacco Advisory Group of the Royal College of Physicians. Harm reduction in nicotine addiction: helping people who can't quit. London: Royal College of Physicians of London, 2007.

97. Gartner CE, Hall WD, Vos T, et al. Assessment of Swedish snus for tobacco harm reduction: an epidemiological modelling study. Lancet 2007;369:2010-14. http:// www.ncbi.nlm.nih.gov/entrez/query.fcgi?cmd=Retrievegdb=PubMedgdopt= Citationglist_uids $=17498798$

98. Citigroup. Tobacco: what if the last smoker quits in 2050? London: Citigroup, 2011.

99. Smith KE, Fooks G, Collin J, et al. "Working the system"-British American tobacco's influence on the European union treaty and its implications for policy: an analysis of internal tobacco industry documents. PLoS Med 2010:7:e1000202. http://dx.doi.org/10.1371\%2Fjournal.pmed.1000202

100. Smith KE, Fooks G, Collin J, et al. Is the increasing policy use of Impact Assessment in Europe likely to undermine efforts to achieve healthy public policy? J Epidemiol Community Health 2010;64:478-87. http://jech.bmj.com/content/64/6/ 478.full.pdf

101. British American Tobacco, MSF, AEEU. Have you ever felt you've been singled out unfairly? British American Tobacco: 321625434-321625451. http://bat.library. ucsf.edu//tid/pre51a99

102. Tiessen J, Hunt $\mathrm{P}$, Celia $\mathrm{C}$, et al. Assessing the impacts of revising the tobacco products directive. Study to support a DG SANCO Impact Assessment. 2010. http:// www.rand.org/pubs/technical reports/TR823.htm

103. Mandal S, Gilmore A, Collin J, et al. Block, amend, delay: tobacco industry efforts to influence the European Union's tobacco products directive (2001/37/EC). Smokefree partnership. Brussels: Smokefree Partnership (in press).

104. Philip Morris International. Philip Morris International's Comments on RAND Europe's final report "Assessing the impacts of revising the tobacco products directive". Philip Morris International, 2010. http://www.pmi.com/eng/ tobacco_regulation/submissions/documents/pmi\%20submission\%20in\%20response \%20to\%20the\%20rand\%20report\%20-\%20public\%20-\%2025\%20october\%202010. pdf (accessed 21 Nov 2011).

105. de Roualle C, Pitcher C. Tobacco lighting up the next decade. New York: Redburn Partners, 2010. 